\title{
La Mano Negra en defensa de la propiedad y el orden: Veracruz, 1928-1943
}

Antonio Santoyo

UAM-I

$\mathrm{E}$ 1 problema central que aquí se revisa es la fuerza política y armada del cacique Manuel Parra Mata, quien tuvo su sede en el municipio de Naolinco, Veracruz, ${ }^{1}$ entre 1928 y 1943 , asícomo su protagonismo en la violenta eliminación del proyecto social y agrario de corte radical impulsado por el gobernador Adalberto Tejeda en esa entidad desde los años veinte. En ese sentido, son relevantes los tipos de relaciones políticas y procedimientos que configuraron la extensa red de poder de aquél. Ubicamos sus vínculos políticos en dos amplias esferas: la de las relaciones "externas", es decir

\footnotetext{
1 Este municipio colinda por el sur con el de Jalapa, capital del estado.
}

aquellas que brindaban influencia, información, orientación y/o protec. ción a Manuel Parra desde altos niveles de los ámbitos gubernamental, económico y eclesiástico, y la de las relaciones "internas", que Parra entablaba con una lógica de patronazgo con propietarios, caciques, pistoleros, funcionarios menores, militares con jurisdicción local y líderes de diverso rango dentro de lo que constituyó su zona de influencia directa (una vasta porción del centro del estado de Veracruz, desde la costa hasta Puebla).

Como marco del desarrollo del tema principal, se presenta el contex to político en que tuvo lugar, al inicio de los años treinta, el fortalecimiento de los sectores enemigos del proyecto social radical del gobernador Adalberto Tejeda. 
En dicha defensa de los intereses de grupos sociales privilegiados en la entidad, Manuel Parra ocupó un lugar destacado. El texto hace referencia tanto al conflicto entre el gobierno central y las aspiraciones y realizaciones revolucionarias sostenidas por la alianza tejedista-campesina, como a las acciones directas que terminaron derrotando a ésta.

Después de revisar la configuración y el sentido de la red de poder parrista, así como la labor de exterminio que llevó a cabo, se hace un balance de su incidencia política en la limitación del reparto agrario y en las organizaciones campesinas y obreras del estado de Veracruz.

\section{ANTECEDENTES DE PARRA}

Las zonas boscosas y mineras aledañas a la ciudad de Pachuca, Hidalgo, fueron el ámbito en que Manuel Parra Mata iniciaría, casi con el siglo, su acumulación de capital. Ahí efectuaría el ensayo de una serie de prácticas y formas de relación política que servirían de punto de partida para el poder económico y político que, durante la cuarta década del siglo, alcanzaría en Veracruz.

Nacido en 1882 en la ciudad de Pachuca, en el seno de una familia de obreros mineros, se vio desde muy joven en la necesidad de realizar también esa actividad. Las terribles condiciones de trabajo en las minas -que determinaron su mala salud por el resto de su vida -2 y sus aspiraciones de

2 Silicosis y angina de pecho fueron los males que sufrió permanentemente y que causaron su muerte a los 61 años. mejoramiento social lo llevaron a buscar por todos los medios a su alcance otro tipo de actividades y de ingresos. Así fue como, mientras efectuaba hurtos a mediana escala y maniobras corruptas contra la compañía en que trabajaba, por su cuenta y en contubernio con empleados administrativos de la misma, pasó primero - poco antes de 1910- a realizar una labor de tipo administrativo en la empresa, puesto desde el cual se facilitaron sus operaciones, para después dedicarse independientemente a la compra y venta de insumos para la industria minera. Pronto concentró su actividad en la explotación, compra y transporte de madera, que entregaba como contratista principalmente a la Compañia Minera Del Bordo. En ese ámbito Parra se sirvió muy frecuentemente de sobornos, coerciones y procedimientos fraudulentos, así como del asesinato -perpetrado por él mismoy, en la mayoría de los casos, por hombres pagados para realizar "el trabajo"- de algunos propietarios de bosques, particulares y comunales, y de empleados gubernamentales que representaron algún obstáculo a sus intereses. ${ }^{3}$

3 Entrevista con Ignacia Licona viuda de Montaño (22 octubre 1980). Ella y su esposo trabajaron durante varios años para Manuel Parra, ella como cocinera y él como chofer; se trasladaron con su patrón de Pachuca a Almolonga (Veracruz) en 1928, año en que adquirió la hacienda. Entrevista con Víctor Filoteo ( 8 noviembre 1980), quien desde su infancia se desempeñó como mozo personal de Parra en la hacienda. A decir suyo, confirmado por otros informantes, "el amo" depositó confianza y aprecio notables en él. Entrevistas con Federico Fabián Zapata (8 diciembre 1980 y 10 diciembre 1986). Se trata de uno de los hombres de mayor edad en Almo- 
La impunidad con que operaba, obedecía en particular a los nexos que entablaba, aprovechando cualquier oportunidad, con autoridades locales y estatales, y en general a la violencia y el desequilibrio que impregnaron la vida pública del país desde 1910.

En numerosas regiones de México el derrumbe del centralismo porfirista, la debilidad $e$ inestabilidad de las autoridades federales, estatales y municipales frente a fuerzas y actores sociales recién aparecidos en la arena polítioosocial; el desorden y la incertidumbre que se manifestaban en numerosas áreas de la economía y, vinculada a esto último, la disminución de poder experimentada por hacendados e industriales ligados al régimen derrocado en 1911, fueron factores, entre otros, que durante la segunda y la tercera décadas del siglo facilitaron la acumulación de capital y de recursos políticos, así como la consiguiente movilidad social, a individuos como Manuel Parra.

Su enriquecimiento como proveedor de madera y otros insumos de varias minas cercanas a Pachuca le per. mitió, desde los últimos años de la década de 1910, adquirir paulatinamente varias propiedades y negocios en el estado de Hidalgo y en la ciudad de México. ${ }^{4}$ Las amistades y contactos de Parra con autoridades y propieta-

longa; con notoria habililidad política ha manejado influencia en el ejido local desde los años cincuenta.

4 Entrevistas con Víctor Filoteo (23 noviem. bre y 3 diciembre 1980). Entrevista citada con Ignacia Licona Viuda de Montaño. Se hace referencia a algunas de esas propiedades en el Archivo del Registro Público de la Propiedad de Jalapa, Ver. (ARPPJ), libro 60., sección primera, año 1928. rios hidalguenses eran ya de un peso significativo hacia 1928. También iban cobrando importancia los vínculos entablados con algunos políticos y con comerciantes y productores de Pue. bla, Tamaulipas, Veracruz y la ciudad de México. Sus actividades económicas lo pusieron en contacto con algunos empresarios de viejo cuño-de los que buscaron sagazmente la sombra protectora del nuevo orden políticoy con empresarios nacientes - de aquellos que empezaban a cosechar los frutos de la revolución en los años veinte debido a la actividad política y/o mili. tar propia o de allegados.

Serían precisamente empresarios sin experiencia -herederos de los militares revolucionarios recientemente retirados, el general Joaquín Fonseca y el coronel Efraín Fonseca-, ${ }^{5}$ que formaban una rama recientemente enriquecida de la familia de su esposa, Lucía Cruz Fonseca, quienes le venderían a Manuel Parra la hacienda cañera de Almolonga en $1928 .^{6}$

La posibilidad de convertirse en el dueño de aquel ingenio y sus tierras le vino a Parra como anillo al dedo: por estricta recomendación médica debía trasladar su residencia a un lugar con poca altitud y un clima preferentemente cálido. Almolonga reunía esas condiciones. Además, se trataba de una unidad de producción susceptible

5 Entrevistas citadas con Ignacia Licona, Federico Fabián y Victor Filoteo. Respecto a esto es pertinente recordar el proceso de desmilitarización de la sociedad impulsado por el grupo Sonora desde que accedió al poder central en 1920.

6 ARPPJ, inscripción 307, libro 60., sección 1a., año 1928. 
de arrojar buenas utilidades, lo que entusiasmó a su nuevo poseedor.

\section{TECNIFICACIÓN Y PRODUCCIÓN DE AGUARDIENTE}

Al adquirir la hacienda -en abril de 1928-Parra emprendió afanosamente su transformación en un centro productivo altamente redituable. Con esa finalidad inició, a unas semanas de su llegada, una vasta reparación y el mejo. ramiento técnico del ingenio. Asimismo, se efectuaron obras para ampliar la zona de irrigación de la hacienda. De modo paralelo se sembraron con caña las parcelas en las que hasta el momento se venía cultivando maíz (por arren. damiento y mediería) y se adquirieron varios cientos de reses de engorda. Entre el terreno que a este ganado se le dio como potrero hubo parcelas usufructuadas, también hasta entonces, por medieros y arrendatarios.

Desde un principio la producción del ingenio de Parra fue elevada, tanto por la fuerte inversión de capital realizada y el intenso ritmo de trabajo impuesto a los trabajadores, como por los recursos y medidas utilizados para ga. nar terreno en el mercado regional. Entre estos medios, pronto cobrarían gran importancia las relaciones de compromiso con terratenientes, comerciantes y autoridades, así como el uso -articulado con sus relacionesde prácticas ilícitas y violentas.

Las dificultades con que se desenvolvía el mercado azucarero veracruzano, y las adversidades traídas por la crisis de 1929, pronto harían ver a $\mathrm{Pa}$ rra las desventajas de concentrarse en la producción de azúcar, cuando la de aguardiente de caña resultaba mucho más lucrativa. Así, vemos que la actividad del ingenio, de 1930 en adelante, se iría orientando hacia la elaboración de esta bebida como producto principal. En 1929 todavía salieron de Almolonga poco más de 500000 kilogramos de azúcar y cerca de 60000 litros de aguardiente. ${ }^{7}$ Esta relación se invertiría radicalmente hasta el punto que, en 1934, la producción de aguardiente sería de 936000 litros (3000 litros diarios) y la de azúcar de unos cuantos miles de kilos, solamente la necesaria para no desperdiciar caña. Raúl Contreras Ferto, contador de la hacienda en aquel entonces, subraya que la producción de azúcar y la cría de ganado "sólo se usaban para camuf lar el verda. dero negocio, la producción y venta de aguardiente con el que Parra tenía inun. dada toda la región central del estado" y algunas zonas limítrofes de Puebla. Aquel mismo año de 1934 cada litro de aguardiente era vendido a 55 centavos, y el kilo de azúcar a 21 centavos, siendo mucho más costosa la elaboración del segundo producto que del primero por la marcada diferencia entre el número de operarios requerido. ${ }^{8}$

A pesar de lo que afirma Contreras Ferto sobre la actividad ganadera como mero "camuflaje" de la producción y venta de aguardiente, resultan innegables la importancia que tenúa para la unidad económica y el interés que Parra ponía en ella. Conforme éste fue expan-

${ }^{7}$ Archivo Municipal de Naolinco (AMN), Estadística Agrícola, 1930.

8 Entrevista con Raúl Contreras Ferto (22 agosto 1981). 


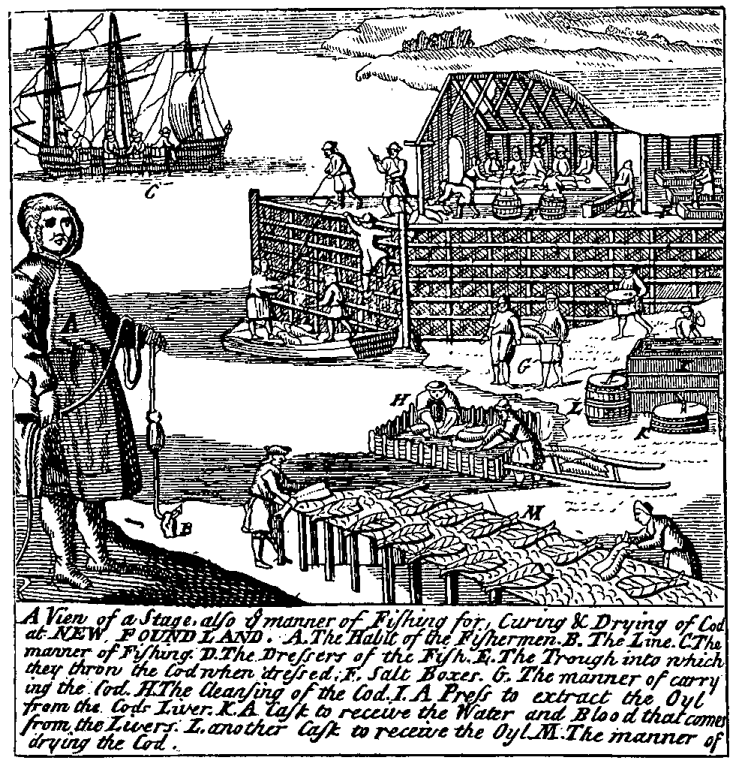

diendo sus intereses y relaciones por la entidad, usufructuó potreros y ganado en diversos sitios, ubicados sobre todo hacia la costa del Golfo.

Por lo que se refiere al crucial cultivo de maíz, el propietario lo obstruyó totalmente desde 1929, viéndose obligada toda la población local a depender exclusivamente del salario. En cambio, Parra amplió y atendió celosamente las fincas de mango y café ya existentes; de la primera se obtenían buenas utilidades cada primavera por la venta de la cosecha en Jalapa, la segunda producía solamente para el consumo local. ${ }^{9}$

La producción azucarera en Veracruz se enfrentó a enormes dificulta-

9 Entrevistas citadas con Victor Filoteo e Ig. nacia Licona viuda de Montaño. des entre 1920 y 1932 , tornándose dramática su situación durante los últimos tres años de dicho periodo. La respuesta individual que muchos productores dieron a tal estado de cosas fue entablar una cruenta competencia con los demás en un afán desesperado de conservar o ampliar sus "zonas de control" en el mercado. Otra medida, que no chocaba con la anterior y con la que algunos productores respondieron a la crisis, fue la disminución de la producción de azúcar y el aumento de la elaboración de aguardiente. Esta respuesta a la dificil situación de la industria conllevaba evidentes ventajas, resumidas en la reducción de los costos de producción.

Esta alternativa, si bien era muy 
atractiva para los dueños de ingenios, no podía ser aplicada por ellos con facilidad, ni en la medida ni con la permanencia deseadas. Los obstáculos al éxito radicaban en los altos gravámenes a la fabricación y comercialización del líquido, que eran estrechamente vigiladas por las autoridades. La posibilidad de produciry vender aguardiente estaba en relación directa con el grado de influencia política y social de cada productor. Desde los primeros años treinta, Manuel Parra "inundó" de aguardiente los municipios de Naolinco, Misantla, Jalapa, Actopan y circundantes. En esta área había otros ingenios y trapiches que se dedica. ban básicamente a la producción de azú. car y piloncillo, como La Concepción, Tenampa y Paso de San Juan, por mencionar algunos.

Es pertinente asentar que un elemento decisivo para la importancia de este producto en la región fue su tradicionalmente elevado consumo, cuan. do la producción industrial y la venta de otras bebidas alcohólicas en el país eran marcadamente inferiores a lo que serían años después. Basta pensar en la posterior irrupción de diversas empresas -entre ellas grandes transnacionales- en la industria de vinos y licores, y en las inmensas ventas que efectúan hoy en día con ayuda de masiva y sofisticada publicidad.

En ese tiempo -señala Contreras Ferto- existian dos licores [de marcas registradas] famosos y casi únicos en la región, dos habaneros. Lo demás era aguardiente, y Manuel Parra tenía el monopolio absoluto. ${ }^{10}$

${ }^{10}$ Entrevista citada con Raúl Contreras Ferto.
Casi la totalidad de las facturas con las que salía de Almolonga el aguardiente no era timbrada. La mayor parte de las veces, los documentos que acompañaban al producto se referían a él como "kilos de café" e iban membre. tados con el sello de la hacienda, lo cual servía de salvoconducto. ${ }^{11} \mathrm{La}$ distribución del aguardiente de Almolonga no encontraba obstáculos. Ya fuera por contubernio de autoridades con Parra, o por temor de las mismas a la acción infalible de pistoleros encargados de "proteger el negocio", los comerciantes que adquirían y distribuían el licor prácticamente no enfrentaban interferencias. Diariamente era enviado a Almolonga un camión, desde la misma capital del estado, por uno de los principales concesionarios. Asimismo, llegaban "burreros" desde múltiples puntos del centro del estado a recoger latas con el líquido.

\section{CONTEXTO POLÍTICO: CONFLICTO ENTRE EL PODER CENTR AL}

Y LA ALIANZA TEJEDISTA.CAMPESINA

A partir del otoño de 1929 , y a lo largo del periodo conocido como maxima. to, el clima político dominante estigmatizó al agrarismo y a sus representantes en la mayor parte del país. No ocurrió así en aquellos estados en los que ciertos líderes revolucionarios - como los michoacanos y los veracruzanos-impulsaban y fortalecían la reforma agraria.

Entre 1928 y 1932 , la fuerza y auto-

11 Entrevistas citadas con Victor Filoteo y Raúl Contreras. 
nomía del movimiento popular que encabezaba en Veracruz el gobernador Adalberto Tejeda ${ }^{12}$ le permitieron a éste oponerse a la política agraria del gobierno federal, así como promover, en general, cambios progresistas en las esferas política, social, cultural y económica de la entidad. El agrarismo radical veracruzano tuvo entonces como soportes, por un lado, la identificación y el compromiso de los líderes tejedistas con los intereses campesinos y, por el otro, las "guerrillas" o milicias agraristas que se habían desligado definitivamente del ejército federal y estaban bajo las órdenes directas de Tejeda.

El acercamiento del gobernante estatal al movimiento campesino se produjo simultáneamente a su distanciamiento respecto de Calles. La lealtad a éste -evidente durante los años anteriores y que le había valido la reelección como gobernador en 1928-, empezó a desvanecerse desde la muerte de Obregón. Tejeda participó activamente, junto con renombrados obregonistas, en las críticas a Calles por las intenciones de perpetuar en sus manos el control del país y de abandonar los principios de justicia social de la revolución mexicana.

El instrumento de control político que buscaba ser el Partido Nacional Revolucionario (PNR) no había logrado, en un primer momento - para pesar de Calles y de los demás líderes partidarios de la institucionalización de la revolución-, aglutinar organizaciones campesinas fuertes, como la Li1932.

12 Ocupó ese cargo en 1920-1924 y 1928 . ga Campesina de Veracruz (LCV) y la Liga Nacional Campesina (LNC). En 1929 éstas estaban ampliamente controladas por el tejedismo. Con el doble fin de debilitar a un poderoso movimiento popular como éste y de fortale. cer al PNR con la incorporación de más organizaciones de masas, Calles buscó tenazmente desde 1930 el acercamiento a los líderes más oportunistas de la liga veracruzana y de la LNC y, a través de ellos, el divisionismo dentro de es. tas organizaciones.

Desde la creación del PNR, el enfrentamiento entre Calles y Tejeda se evidenció, pues este último no quiso poner a disposición del poder central el control de las masas campesinas vera. cruzanas e impidió que los callistas se adueñaran de la dirección del PNR en Veracruz. En cambio, permitió que dicha dirección recayera en manos de agraristas radicales, quienes promovieron a campesinos auténticos como candidatos del partido. Calles y el PNR no podían tolerar tanta autonomía; por ello, además de fomentar sistemáticamente divisiones dentro de las ligas campesinas radicales y de promover la creación de ligas campesinas oficialistas (conocidas genéricamente como "blancas" o "amarillas") que se incorporaran al partido, se propusieron desarmar a las guerrillas y recuperar, por todos los medios, el control del PNR estatal. ${ }^{13}$ Estos objetivos, que representaban el aniquilamiento de la alianza tejedista-campesina, empezaron a ser al canzados progresivamente desde fines de 1932.

13 Martínez Assad, "Lucha", 1977; Falcón, Agrarismo, 1977, p. 91. 
Las acciones del gobierno federal contra la autonomía de la alianza tejedista-campesina experimentaron una especial intensidad al ser orientadas contra la fuerza que respaldaba los logros del movimiento: su brazo armado. En diciembre de 1932 el presidente Abelardo Rodríguez ordenó oficialmente el desarme definitivo. Una semana después, el general Lázaro Cárdenas, quien ese mes había sido nombrado secretario de Guerra y Marina, repitió las mismas órdenes al jefe de operaciones militares de la entidad. Según Cárdenas, el gobierno federal estimaba "en lo que valen" los servicios prestados por los batallones agraristas, pero las condiciones de paz en que se hallaba el país hacían innecesa- ria su existencia. Agregaba Cárdenas que

el procedimiento de recoger las armas a las defensas populares y la presencia de las fuerzas federales en aquella entidad no persiguen más fin [...] que el aseguramiento de la tranquilidad de los campesinos [...] y librarlos de las maniobras de agitadores profesionales. ${ }^{14}$

Las justificaciones dadas por las autoridades federales al desarme de los campesinos veracruzanos perdían toda validez con sólo observar que se dejaba intactas a las milicias campesinas de otros estados como San Luis Po-

14 Falcón, Agrarismo, 1977, p. 116; Fowler, Movilizactón, 1979, p. 148; Martínez Assad, Revolucionarios, 1982, pp. 164-166.

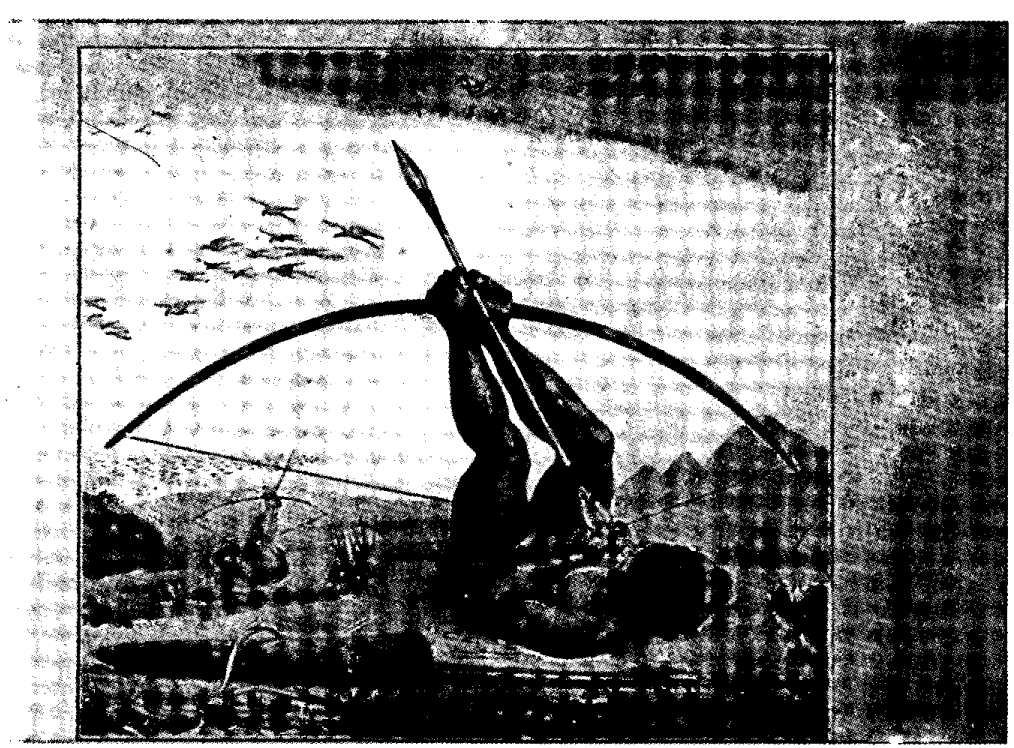


tosí, Zacatecas, Guanajuato, Méxioo y hasta las auspiciadas por el mismo Cárdenas en Michoacán. Para los sectores de revolucionarios partidarios de actuar dentro de las instituciones y reglas establecidas -ya fueran "veteranos" (léase callistas) o "agraristas" (léase cardenistas)- se había convertido en urgente necesidad el aniquilamiento del radicalismo agrario del movimiento social que encabezaba Adalberto Tejeda. ${ }^{15}$

A partir del desarme (cuyo operativo definitivo tuvo lugar el 10 de enero de 1933), los ataques contra Tejeda, la Liga Campesina de Veracruz y la Liga Nacional Campesina arreciaron en los niveles estatal y nacional. En las ofensivas lanzadas dentro de la entidad sobresalió el Comité Revolucionario Veracruzano, organización cardenista que empezó a acusar a los tejedistas de explotar a los campesinos y de ser "oomunistas". También participó en los ataques una facción disidente de la Liga Veracruzana, encabezada por Sóstenes Blanco y auspiciada por las autoridades centrales y diputados federales veracruzanos como Manuel Jasso, reconocido ex tejedista. Por su parte, el Partido Comunista ase. guró en enero de 1933 que estaba en contra de las acciones del PNR y del desarme pero, "en primer lugar y ante todo, contra Tejeda". ${ }^{16}$

Paralelamente a la vertiginosa y efectiva acción contra el brazo armado del tejedismo, se intensificaron las medidas patrocinadas por el gobierno federal para debilitar aún más su base

15 Cárdenas, Apuntes, 1972, pp. 229-230.

16 García Ochoa, "Memorias", 1977; Martinez Assad, "Lucha", 1977; Falcón, Agrarismo, 1977 , p. 119. política en el estado. Dichas acciones se dirigieron contra la independiente Liga Veracruzana y contra los ayuntamientos tejedistas.

\section{El poder de Manuel Parra}

El derrumbe de la alianza tejedistacampesina fue seguido por un periodo de virtual vacio de poder y caos político en la entidad. La conjunción de fenómenos como el aniquilamiento político de los tejedistas, el debilitamiento y división de la Liga Campesina y el desarme de las guerrillas, desembocó en un fortalecimiento de las posiciones conservadoras en todos los ámbitos de la vida local. El desarrollo del terrorismo antiagrarista, y derechista en general, fue paralelo al abandono casi absoluto de la reforma agraria y los derechos laborales por parte de los gobernantes veracruzanos.

Desde el momento mismo en que se intensificaron las acciones oficiales en contra del agrarismo tejedista, se hizo visible el proyecto revanchista de los sectores sociales conservadores del estado en contra de aquél. Este proyecto derechista incluyó la participación activa de políticos y militares antitejedistas, terratenientes, industriales, comerciantes, clero y medios de comunicación, así como de la fuerza armada de numerosas guardias blancasy, en no pocas ocasiones, del mismo ejército federal. Caso sobresaliente y representativo de la cruenta militancia antiagrarista fue el de Manuel Parra Mata, quien desde la segunda gubernatura de Adalberto Tejeda se distinguió por su rebeldía violenta a la política del 
ejecutivo estatal. Poco después encabezaría la represión extensiva y sistemática del agrarismo en gran parte del estado. ${ }^{17}$

Como ya mencionamos, al reactivar económicamente la hacienda de Almolonga, ${ }^{18}$ Parra impuso sobre los trabajadores la dependencia exclusiva del salario para subsistir; éstos, además de verse desprendidos definitivamente del arrendamiento y la mediería, fueron sometidos a una explotación severa. En ese contex to, renació entre los ex integrantes del sindicato agrario local que no habían emigrado del lugar, el proyecto de reorganizarse, a inicios de 1929, para plantear demandas laborales y agrarias. ${ }^{19}$ La respuesta patronal fue inmediata: Parra empezó a despedirlos uno a uno y a ejercer acciones violentas contra ellos a través de empleados y trabajadores de su confianza para expusarlos del poblado. ${ }^{20}$

La reorganización sindical estaba todavía en sus inicios y sin haber con-

17 García Ochoa, "Memorias", 1977.

18 La unidad productiva que compró había vivido periodos florecientes anteriormente, pero por una gama de adversidades económicas y conflictos sociopolíticos desarrollados antes de 1928, la bonanza de la hacienda era nula para ese año.

19 Secretaría de la Reforma Agraria (SRA), Almolonga, exp. 16406.

20 Dicho sindicato se había formado en 1921 , bajo los auspicios de los trabajadores comunistas de la fábrica textil San Bruno, en Jalapa. Después de una breve etapa de combativas y relativamente exitosas acciones, la crisis financiera de la hacienda contribuyó ampliamente a la ruina de la organización antes de 1924. Entrevistas con Matías Pérez Rivera ( 7 noviembre 1980 y 10 diciembre 1986). AMN, Correspondencia Presidencia Municipal, 1922; Sindicatos, 1923, y Trabajo y Previsión Social, 1923. seguido apoyo en Jalapa, cuando comenzó la hostilidad contra ella. La falta de respaldo respondió a las divisiones que para mediados de 1929 se vivían dentro de la Cámara del Trabajo de la capital del estado entre el PCM y la CROM. ${ }^{21}$

Al finalizar diciembre de 1929 fueron brutalmente golpeados y amenazados de muerte los últimos sindicalistas -alrededor de diez- que quedaban en Almolonga. Una madrugada del mes siguiente, tras recibir una "información filtrada", salieron huyendo de la hacienda con sus familiares y sus pocas pertenencias, poniéndose a salvo de la "limpia definitiva" ordenada por el patrón a sus guardias. ${ }^{22}$

En un clima social como aquél no es dificil imaginar la situación prevaleciente respecto de las demandas agrarias. A los intentos de reivindicación agraria de poblaciones cercanas como Alto Lucero, Alto Tío Diego, Tepetates y la misma Almolonga -unos más atrevidos que otros- respondió Parra con la violencia de sus pistoleros. ${ }^{23}$

Desde 1929 Parra se empeñó en la tarea de hacerse de un brazo armado y ampliar su ya existente red de relacio. nes con individuos influyentes, política y militarmente, para apuntalar sus intereses. A mbos objetivos eran ya

21 Domínguez Pérez, "Comunistas", s. f., pp. 224-252.

22 Diversas entrevistas con testigos directos de los acontecimientos, efectuadas en agosto y septiembre 1981, así como durante los veranos de 1986 y 1988.

${ }^{23}$ Archivo de la Comisión Agraria Mixta del Gobierno del estado de Veracruz (ACAM), Expedientes de restitución de los pueblos de Almolonga, Alto Lucero, Alto Tro Diego y Tepetates. 
una realidad en 1931 y le permitieron enfrentar al tejedismo con gran éxito, mientras en el resto del estado la oposición violenta de los terratenientes a la política del gobernador no podía rebasar ciertos límites.

Parra blandió como justificación de su actitud y procedimientos la urgente necesidad de "seguridad, disciplina y respeto" que, según él, tenían los ciudadanos laboriosos y honrados, por lo cual debía imponerse orden a cualquier precio. En Naolinco y los municipios vecinos, como ocurrió en otras partes de Veracruz, la despolitización y en ocasiones la frustración que llegó a caracterizar a algunos grupos agraristas armados, los llevó a cometer actos sin ninguna incidencia favorable a las transformaciones perseguidas por el tejedismo y que sí fueron claras acciones de violencia y atropello contra la población civil. Estos hechos fueron ampliamente capitalizados por los sectores conservadores veracruzanos y nacionales en su discurso contra la alianza tejedista-campesina. Con ellos se quiso identificar y definir al movimiento agrario, interpretando tendenciosamente su verdadero contenido. Dicha situación se manifestó en Naolinco y de manera significativa en el caso de Manuel Parra. El pretexto particular utilizado por el cacique para llevar al extremo sus medidas fue haber sufrido un secuestro por parte de una banda armada, que consiguió un rescate de 10000 pesos a cambio de su vida, en la primavera de 1931. En Almolonga y sus alrededores quedan ahora múltiples versiones sobre aquel suceso que quedó envuelto en un halo mítico y fue convertido en lección mo- ral para los infractores de las "buenas costumbres". El secuestro se hizo célebre y se transformó en una justificación del terrorismo antiagrarista, aceptado en no pocas ocasiones hasta en los sectores sociales que fueron sus víctimas. ${ }^{24}$

En su búsqueda de apoyo entre políticos y militares con poder y fuero a nivel federal, Parra halló condiciones muy favorables en la tónica de la política nacional durante el maximato. Desde entonces estableció vínculos con parientes cercanos de Abelardo L. Rodríguez y, a través de ellos, con encumbrados miembros de la familia revolucionaria, como el mismo presidente Rodríguez y el general Pablo Quiroga Escamilla. ${ }^{25}$

El éxito de la producción alcoholera de Almolonga, así como la influencia y poder que ganó su propietario sobre autoridades civiles y militares, tuvieron que ver directamente con la vinculación política y empresarial de Parra con el general Quiroga. Éste figuró durante aquellos años en muy altos niveles del gobierno federal, así como del gobierno del estado de Nuevo León, lo que le valió una amplia ascendencia en el ámbito político a nivel nacional. Como oficial mayor de la Secretaría de

${ }^{24}$ Además de las entrevistas citadas, diversos corridos e interpretaciones de los hechos, registrados a partir de 1981 por el autor en los municipios veracruzanos de Naolinco, Misantla, Actopan, Jalapa y Coatepec. Hernández Pérez, Corridos, s. f.

25 Entrevista con Manuel Zorrilla Rivera ( 4 noviembre 1980). Se trata de uno de los líderes cardenistas más destacados en Veracruz durante los años veinte y treinta. Estuvo estrechamente vinculado a Manlio Fabio Altamirano, candidato cardenista a la gubernatura del estado, asesinado en junio de 1936 por pistoleros de Manuel Parra. 
Guerra y Marina y como jefe del Departamento de Establecimientos Militares durante la presidencia de Pascual Ortiz Rubio, respaldó las acciones que Parra efectuaba contraviniendo la política del gobernador Tejeda. A partir del plagio sufrido, el empresario se convenció de la pertinencia de asegurarse una cobertura total. Concibió la idea de ofrecerle al general Quiroga la mitad de la propiedad de Almolonga, propuesta que aquél aceptó inmediatamente y que le valió a Parra el nombramiento no oficial de coronel, así como la asignación a la hacienda de un destacamento federal permanente. ${ }^{26}$

26 Quiroga fue copropietario de la unidad productiva desde los últimos dias de 1931. ARPPJ, inscripción 602, sección 2a., año 1943; inscrip-
Otras relaciones definitivas para Manuel Parra fueron sus estrechas amistades con el obispo Manuel Pío López y con el gobernador que sucedió a Tejeda, Gonzalo Vázquez Vela (1932-1936). Las frecuentes visitas de éste a la hacienda llegaron a constituir verdaderos eventos políticos de apoyo al cacique, en los que dirigentes de la oficialista Liga Blanca atacaban al agrarismo tejedista y ensalzaban a la "gente de trabajo", como el anfitrión.

Ya en 1933 Parra se entrevistaba cotidianamente, en su despacho, con oficiales del ejército federal, autoridades del poder judicial, presidentes municipales de la región -que eran impues-

ción 88, sección 2a., año 1944. Entrevista citada con Manuel Zorrilla Rivera.

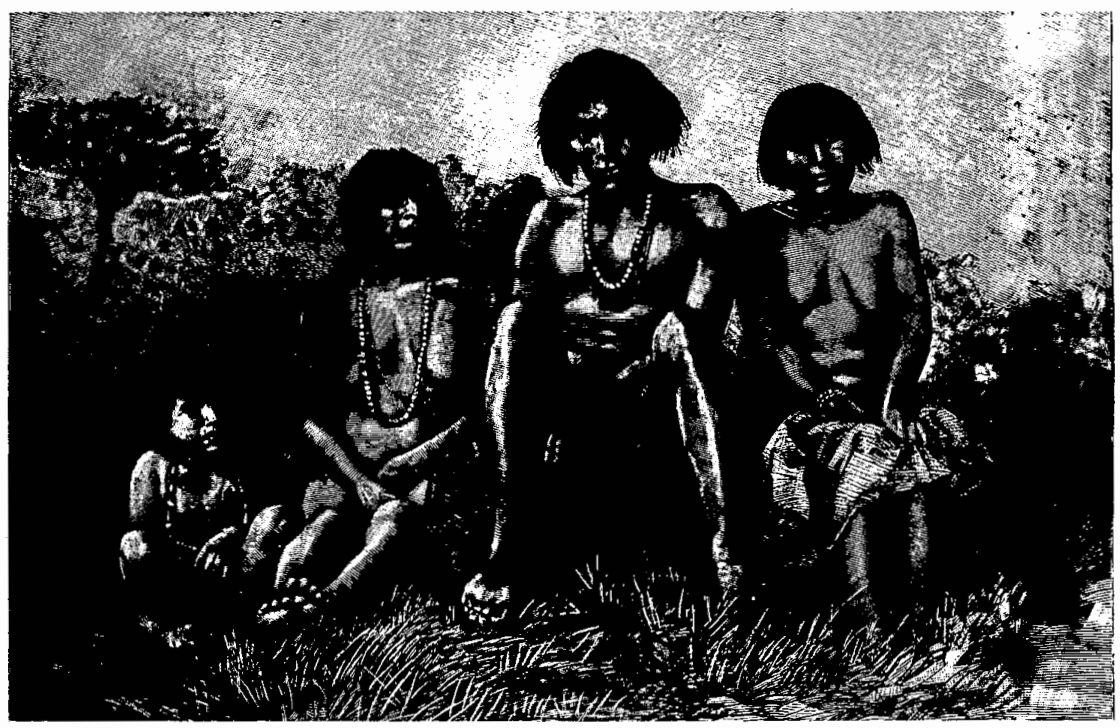


tos y manejados por él-, diputados y senadores, así como con fuertes comerciantes e industriales del estado.

Pese a que en junio de 1935 Pablo Quiroga fue destituido por Cárdenas como secretario de la Defensa -como parte de la resolución de su enfrentamiento con Calles-, 27 el desenvolvimiento del parrismo no sufrió mella alguna. A pesar también de las innumerables declaraciones del presidente Cárdenas, del nuevo secretario de la Defensa, Andrés Figueroa, y de jefes del ejército federal en Veracruz -como Heriberto Jara, comandante de la 26 zona militar en 1935 y supuesto simpatizante del agrarismo-28 en contra de la violencia latifundista, $y$ advirtiendo que se armaría a los campesinos, a éstos en Veracruz se les dejó inermes frente a aquélla.

Durante el último tercio de los años treinta y el primero de los cuarenta, cobró singular importancia para los dueños de Almolonga su relación con los hermanos Manuel y Maximino Ávila Camacho. El primero, secretario de la Defensa Nacional desde 1937 y presidente de la república a partir de 1940; el segundo, gobernador del esta-

27 La posición de Quiroga se vio favorecida en diciembre de 1932, cuando fue designado subsecretario de Guerra y Marina por Abelardo Rodríguez, y llegó a ser aún mejor poco tiempo después, cuando se le nombró secretario de la Defensa Nacional, al parecer impuesto por Calles, en el gabinete de Cárdenas.

28 El mismo Heriberto Jara era visitante asiduo de Parra. Otros jefes de operaciones militares en Veracruz, como los generales Mange y Soto Lara, tuvieron también excelentes relaciones con el hacendado. Entrevista con Ignacia Licona (22 agosto 1981) y entrevistas citadas con Victor Filoteo. do de Puebla de 1937 a 1941 . La relación principal era con Maximino, quien tenía fuertes intereses terratenientes y comerciales en el estado de Puebla y en el norte de Veracruz. ${ }^{29}$

Otra esfera constitutiva de la amplia red de poder parrista la formaban aquellos vínculos en los que el cacique ocupaba el polo dominante. Desde 1929 Parra entró en contacto con caciques y hombres fuertes locales debido a las necesidades de comercialización de su aguardiente a partir de una zona en principio reducida pero que rápidamente llegaria a tener un radio, en varias direcciones, mucho mayor a los 50 kilómetros desde Almolonga. Se trataba de personajes con mayor o menor poder personal, pero todos integrantes de una heterogénea clientela política y económica que recibía la sombra protectora de "don Manuel".

En sus respectivos "territorios" o áreas de influencia, controlaban la lucrativa comercialización del aguardiente. Junto con el aprovechamiento de dicho mercado, comúnmente man. tenían el control de otros recursos: tierras, agua, fuerza de trabajo, poder político formal $y / o$ informal, fuerza armada, etc. La protección que pudo dar Parra a esos detentadores de poder local fue la vía para expandir su control e influencia a una muy vasta porción del centro de la entidad, llegando con los años a incidir en zonas de Puebla, Hidalgo, Tamaulipas y Tabasco.

29 Agetro, Luchas, s. f., pp. 233-236. La Voz del Campesino, 23 agosto y primera quincena septiembre 1941. Entrevistas citadas con Victor Filoteo. 
Las relaciones patrón-cliente entabladas entre "don Manuel" y aquellos terratenientes, comerciantes, industriales, funcionarios, militares y líderes sociales, se caracterizaban en su mayor parte, en cuanto se refiere a los clientes, por la aportación de lealtad, estima, información confidencial para el afianzamiento del patronazgo y apoyo político, incluyendo la contribución directa o indirecta para eliminar físicamente a enemigos localizados. En otros casos - presentes sobre todo a partir del segundo lustro de los años treinta-, la participación de los clientes se materializó en el pago de "cuotas" $^{n 0}{ }^{30}$ Esto distinguió a ciertos propietarios que no quisieron hacer muy visible su relación con el parrismo o que se vieron forzados a ligarse a él estando de por medio sus intereses.

El violento control sobre un amplio territorio del centro del estado tuvo como respaldo al ejército federal; pero su instrumento directo fue un numeroso contingente de pistoleros. Los lugartenientes de Manuel Parra fueron en muchos casos los mismos caciques de cada poblado bajo control. Éstos tuvieron bajo sus órdenes directas a trabajadores armados y a pistoleros de tiempo completo. Con la coerción armada sobre los campesinos y trabajadores asalariados -principalmente de ingenios- de la zona central del estado, la explotación económica y política de éstos fue llevada al extremo. La opresión y el miedo de aquellos años se sintetizan en el nombre que el sentir

30 Estas cuotas mensuales fluctuaban entre uno y cinco pesos por hectárea o cabeza de ganado mayor en posesión del cliente. popular dio a la organización parrista: La Mano Negra.

Parece significativo que durante los dos primeros años del gobierno presidencial de Lázaro Cárdenas fueran re. portados en Veracruz los asesinatos de poco más de 2000 personas a manos del terrorismo antiagrarista. ${ }^{31}$ Según una fuente escrita, con la que coinciden testimonios orales recogidos, pudo ascender hasta 40000 el número de personas asesinadas por los pistoleros parristas a lo largo de poco más de diez años. ${ }^{32}$ Resultaba dramático que las milicias campesinas veracruzanas hubieran sido desarmadas en 1932 y 1933 , y ahora el gobierno federal no respondiera a las peticiones de armas que ha. cían los agraristas y sus comunidades para defenderse.

Las operaciones de La Mano Negra no eran hechos aislados o espontáneos. Respondían a un proyecto social definido y a una campaña sistemática de los propietarios para conservar y ampliar sus privilegios. Contrastando con lo que ocurría en gran parte del país con el comienzo de Lázaro Cárdenas como presidente, en Veracruz los campesinos no podían ya hacer frente al terrorismo latifundista. Al parecer, el presidente veía que en la alianza tejedista-campesina subyacía un proyecto político-social estorboso para la modernización económica del país y para el fortalecimiento de la figura presidencial -además de que aspiraba al control pleno de las masas trabajado-

${ }^{31}$ La Voz de México, segundo semestre 1935 y primer semestre 1936. Excélsior, segundo semestre 1935 y primer semestre 1936.

32 García Ochoa, "Memorias", 1977. 
ras y a la pacificación definitiva del territorio nacional-, por lo que no dio respuesta efectiva a las desesperadas peticiones de armas y permiso para organizar guerrillas nuevamente. Su respuesta se limitó a una serie de declaraciones en las que llegó a amenazar con armar a los campesinos y la entrega, a través del jefe de operaciones militares, de unos cuantos fusiles a algunos cuerpos de defensa rural -que por su núme. ro no tuvieron la menor efectividad frente a la fuerza de las guardias blancas. ${ }^{33}$ En la nueva correlación de fuerzas sociales, a nivel nacional y estatal, el campesinado de Veracruz no encontró ya ningún aliado.

LIMITACIÓN DEL REPARTO AGR ARIO Y CONTROL PARRISTA DE ORGANIZACIONES CAMPESINAS Y OBRER AS

El clima social y político impuesto por el parrismo en el centro de la entidad -que contribuyó a hacer más dramático el abatimiento del tejedismo propiciado por el poder central-fue uno de los mayores obstáculos a la entrega efectiva de tierras dictada por resoluciones de los gobiernos federal y estatal. Un indicador de esto es que de las 355 resoluciones dictadas para Veracruz por el gobierno de Abelardo Rodríguez, únicamente 51 fueron ejecutadas.

Además de dificultar la entrega de tierras a los campesinos del estado, la

${ }^{33}$ La Voz de México, segundo semestre 1935 y primer semestre 1936. Excélsior, segundo semestre 1935 y primer semestre 1936. Entrevistas con César Rivadeneyra de Guevara (25 agosto 1981 y 10 agosto 1986 ). violencia y el caos político asociados a la derrota de la alianza tejedista-campesina reafirmaron al poder federal en su intención de controlar a los campesinos y obreros veracruzanos a través de su reagrupamiento y corporativiza. ción. Este proyecto venía ya desenvolviéndose seriamente a nivel nacional por el trabajo de los revolucionarios agrupados en torno a Lázaro Cárdenas. En Veracruz su implantación tuvo que enfrentarse no sólo al radicalismo tejedista; también, posteriormente, a las fuerzas que hicieron el "trabajo sucio" de eliminarlo violentamente.

Manuel Parra promovió en el centro del estado la creación de agrupaciones campesinas totalmente conformistas, manejando a dirigentes de línea antitejedista (de la Liga Blanca) y aun de supuesta filiación tejedista (de la Liga Roja). Tales organizaciones, que llegaron a reunir a miles de campesinos, estuvieron bajo su pleno dominio y contendieron con la llamada Liga Unificada -logro político del gobernador Miguel Alemán en 1937-durante el último tercio de los años treinta y hasta bien entrada la década siguiente. ${ }^{34}$

Los parristas también se dedicaron a organizar sindicatos blancos en algunos ingenios del centro de Veracruz con la expresa finalidad de oponerse al ascenso de la CTM. El poder de ésta en la entidad hacia inicios de los años cuarenta alarmó al gobernador Jorge Cerdán (1940-1944) -una de las figuras más antidemocráticas del ámbito vera. cruzano-, quien se dedicó a combatir-

34 García Ochoa, "Memorias", 1977; Agetro, Luchas, 1942, pp. 233-236. 
la en estrecha asociación con Manuel Parra. ${ }^{35}$

\section{OBSERVACIONES FINALES}

Las organizaciones campesinas $y$, en menor proporción, las obreras impulsadas por el tejedismo, se caracterizaban hacia la segunda gubernatura de su principal dirigente (1928-1934) por un alto grado de autonomía y radicalismo social, adversos a los proyectos de centralización e institucionalización del poder contemplados por el callismo y por el cardenismo.

Desde el arranque de los años treinta, el panorama enfrentado por Cárdenas en Veracruz no fue simple en modo alguno. El movimiento social en este estado no aceptó transigir y aliarse a las propuestas de aquél. Esto hizo que el general michoacano, al pretender ganar apoyos para su proyecto político-social y para sus aspiraciones presidenciales, se empeñara en la destrucción del movimiento popular jarocho, primeramente, y en su control y subordinación, de manera posterior.

En este contexto, el poder parrista pudo servir al bloque político y social dominante para subordinar a los cam. pesinos y trabajadores de una extensa superficie del estado a partir de la desarticulación de su movimiento radical en 1932-1933. Precisamente, durante los primeros años de preeminencia del parrismo, los instrumentos, representados por las organizaciones oficiales de masas creadas por los revolucionarios triunfantes, no tenían aún suficiente

35 Loc. cit. fuerza en Veracruz para garantizar un control efectivo de los trabajadores.

Desde la destrucción del poder tejedista-campesino, la libertad y apoyos de que gozaba Parra lo llevaron a desafiar violentamente al populismo cardenista y sus paulatinos avances en el fortalecimiento de organizaciones de masas como la CNC y la CTM. Esta agresividad se agudizó al acercarse el fin del periodo presidencial de Cárdenas y durante los primeros años cuarenta. Entonces, contando con la firme colaboración del gobernador Cerdán y el respaldo de los hermanos Ávila Camacho, el cacique alcanzó la cúspide de su poder.

El poder que había obtenido el parrismo en el ámbito político y social veracruzano en general, y frente a los movimientos campesino y obrero de la entidad, era prueba irrefutable del éxito sobre el proyecto social tejedista, capitalizado por los sectores más antidemocráticos de la sociedad veracruzana. Sin embargo, tal éxito no correspondía exclusivamente a estos sectores; era también, hasta cierto punto, encarnación de la victoria de esta parte de la familia revolucionaria, enemiga de la autogestión y de las concepciones sociales radicales del proyecto tejedista, que las tenía como fundamento de la revolución mexicana.

Entre 1928 y 1933 Cárdenas había estado en oposición al movimiento encabezado por Adalberto Tejeda, tanto por lo excluyente de las ambiciones personales de ambos dirigentes, como porque el tejedismo, según sus postulados, deseaba recuperar las preocupacionesy bases sociales de la revolución, impulsar la autogestión de éstas y terminar a mediano o largo plazo con el capitalis- 
mo. Pero el proyecto que el michoacano representaba aspiraba a una modernización de las relaciones capitalistas y al fortalecimiento centralizado del Estado apoyado en las masas.

Posteriormente, conforme se fue fortaleciendo a nivel nacional y local, el cardenismo se enfrentó también de manera frontal con el parrismo. Esta confrontación encuentra su explicación última en el hecho de que Manuel Parra tenía una perspectiva económica y política de carácter parcial, individualista $-y$ brutal en sus métodos-, mientras que el proyecto cardenista sostenía una visión global, articulada y fundada en premisas liberales de corte más social que individualista.

Al fallecer Manuel Parra - por enfermedad, en mayo de 1943- se empezó a desmoronar la rígida y ampliad red de relaciones políticas verticales que lo había tenido como su piedra sillar. A partir de entonces, los regímenes posrevolucionarios penetraron en los reductos parristas, lenta pero firme e irreversiblemente. Dicha penetración habría llegado incluso si Parra hubiera muerto años después, ya que la viabilidad de un proyecto de sociedad como el suyo, frente al que desarrollaba el Estado, era limitada. No ofrecía al sistema garantías plenas de control, flexible y prolongado, de obreros y campesinos. Por implicar serias desventajas para la dinamización y modernización de las relaciones capitalistas, desde la perspectiva de la elite político-económica, la lógica y la dinámica parristas estaban condenadas a la disolución conforme dejaran de serle útiles, como lo fueron, al proyecto hegemónico.

La modernización impulsada por los gobiernos estatales y federales que se sucedieron desde los años cuarenta, incluyó la destrucción absoluta o parcial (según las condiciones de cada caso) de los sistemas caciquiles, pero en todos ellos refuncionalizando vínculos de patronazgo y encauzando el ejercicio del poder local y regional a través del partido oficial y diversas dependencias gubernamentales. La dominación parrista no podía ser la excep. ción.

\section{BIBLIOGR AFÍA}

-Agetro, Leafar, Las luchas proletarias en Veracruz. Historia y autocritica, Barricada, Jalapa, 1942.

-Cárdenas, Lázaro, Apuntes, 1913. 1940, UNAM, México, 1972.

-Domínguez Pérez, Oliva, "Un estudio de caso: los comunistas de San Bruno", Anuario II, Centro de Estudios Históricos, Universidad Veracruzana, Jalapa, s. f.

-Falcón, Romana, El agrarismo en Veracruz. La etapa radical (1928-1935), El Colegio de México, México, 1977.

-Fowler Salamini, Heather, Moviliza. ción campesina en Veracruz (1920. 1938), Siglo XXI, México, 1979.

-García Ochoa, José, "Memorias de...", manuscrito, Jalapa, 1977.

-Hernández Pérez, Alfonso, Corridos sobre el agrarismo en Veracruz, Centro de Estudios Históricos Universidad Veracruzana, Jalapa, s. f. (Serie Testimonios, año 2, núm. 2).

-Martínez Assad, Carlos, "La lucha campesina en Veracruz entre 1923 y 1934: un intento de organización independiente", Cuadernos Agrarios, núm. 5, México, 1977. , y otros, Revolucionarios fueron todos, Secretaría de Educación Pública/Fondo de Cultura Económica, México, 1982. 


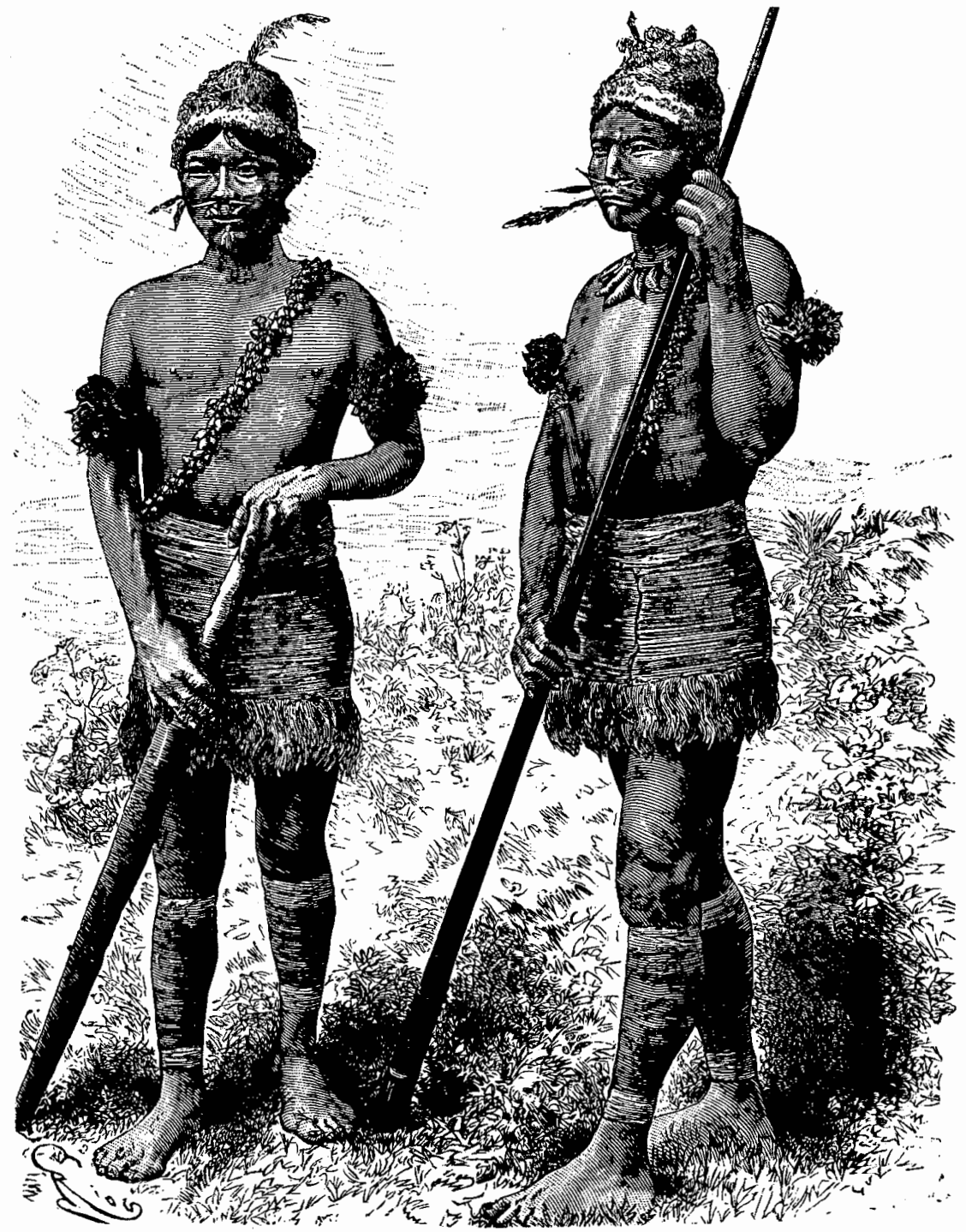

